\title{
Comparison of Single Agent Gemcitabine and Docetaxel in Second-Line Therapy for Advanced Stage Non-Small Cell Lung Cancer in a University Hospital in Turkey
}

\author{
Fatma Yıldırım ${ }^{1 *}$, Ayse Baha², Ahmet Selim Yurdakul ${ }^{1}$, Can Ozturk ${ }^{1}$
}

\begin{abstract}
Purpose: To compare the efficacy and toxicity of gemcitabine versus docetaxel in a second-line setting of nonsmall cell lung cancer (NSCLC) patients previously treated with platin-based combination chemotherapy. Materials and Methods: We retrospectively evaluated the medical records of 57 patients treated with single agent gemcitabine or docetaxel in second-line setting of advanced NSCLC who received one prior platinumbased therapy. Results: The mean age was $56.7 \pm 8.39$ years with $55(96.5 \%)$ males and two $(3.5 \%)$ females. Forty of them received docetaxel and 17 gemcitabine. The mean number of chemotherapy cycles was $6.8 \pm 4.0$ in the gemcitabine group, while it was $4.6 \pm 3.0$ in the docetaxel group. Overall response rates were $8 \%$ and $12 \%$ $(P=0.02)$ for gemcitabine and docetaxel, respectively. The median survival time was 22 versus 21 months for gemcitabine and docetaxel, respectively. The median times to progression were 8 and 5 months. There was no difference between the two groups in terms of incidence of adverse affects $(40 \% v s 47.1 \%)$. All of the hematological side effects were grade $1 / 2$. No major toxicity was encountered necessitating stopping the drug for either group. Conclusions: Treatment with gemcitabine demonstrated clinically equivalent efficacy with a significantly improved safety profile compared with those receiving docetaxel in the second-line setting for advanced NSCLC in this study. Based on these results, treatment with gemcitabine should be considered a standard treatment option for second-line NSCLC.
\end{abstract}

Keywords: Gemcitabine and docetaxel - second-line therapy - advanced stage non-small cell lung cancer

Asian Pac J Cancer Prev, 16 (17), 7859-7865

\section{Introduction}

Lung cancer is one of the most common causes of death among malignant tumors (Cobo et al., 2007). Despite an increasing proportion of patients with advanced non-small cell lung cancer (NSCLC) derive prolonged survival with novel chemotherapy regimens; many of them will require second-line chemotherapy after relapse (Kosmas et al., 2007). Several agents including docetaxel, gemcitabine, pemetrexed and erlotinib have shown to be effective in the second-line chemotherapy for advanced NSCLC (Hertel et al., 1990, Lund et al., 1993, Fossella et al., 2000, Shepherd et al., 2000, Juergens et al., 2007).

Gemcitabine (20, 20-difluorodeoxycytidine) is a nucleoside analog that possesses a unique mechanism of action that provides a much wider range of antitumor activity (Hertel et al., 1990, Lund et al., 1993). There was no randomized study comparing single agent gemcitabine with other agents known to be effective in the second-line setting.

Docetaxel, which is a semisynthetic taxane analogue with definite activity in patients with NSCLC and its value as a single agent has been determined in patients with NSCLC with exposure to prior treatment. Docetaxel monotherapy, at a dose of $100 \mathrm{mg} / \mathrm{m}^{2}$ administered once every 3 weeks, has shown promising activity as a secondline treatment for NSCLC (Fossella et al., 2000, Shepherd et al., 2000).

In this study, we evaluated the affectivity and toxicity profiles of single agent gemcitabine and docetaxel in the second-line setting of advanced NSCLC patients previously treated with a combined platinum-based therapy

\section{Materials and Methods}

We retrospectively evaluated the medical records of 57 patients treated with single agent gemcitabine or docetaxel in second-line setting of advanced NSCLC. The inclusions criteria were as follows: Patients with histologically confirmed advanced NSCLC, Eastern Cooperative Oncology Group (ECOG) performance status (PS) 0-2, progression during or after the completion of one prior platin-based combined chemotherapy, no history of other malignancies and age 18-75 years. Patients with brain metastases were eligible if they had been irradiated, 
Fatma Yuldirlm et al

the brain lesions were radiologically stable and clinical improvement was evident.

Treatment consisted of IV gemcitabine $1.250 \mathrm{mg} / \mathrm{m}^{2}$ on days 1 and 8 , followed by a 1 -week rest repeated every 3 weeks and IV docetaxel $75 \mathrm{mg} / \mathrm{m}^{2}$ in a 3-week schedule.

Doses were reduced by $50 \%$ if patients experienced leukopenia (WBC $\backslash 1.500 / \mathrm{dl}$ ) and thrombocytopenia (platelet $\backslash 100.000 / \mathrm{dl}$ ). Chemotherapy was omitted if WBC count less than 1.000/dl and platelet less than 50.000/dl. Treatment was stopped if disease progression or major toxicities occured or according to physician's decision.

Evaluation of response was performed every two cycles of therapy with computed tomography scans of the chest. Responders were defined as complete response (CR, disappearance of assessable disease) or partial response (PR, reduction of more than $50 \%$ of the lesion of the two largest tumor diameter). Stable disease (SD) meant less than $25 \%$ increases in tumor size. Progressive disease (PD) was defined by an increase of more than $25 \%$ in tumor size.

The overall survival (OS) time was calculated as the period from the start of chemotherapy until death from any cause or until the date of the last follow-up. Overall survival times were estimated by the Kaplan-Meier method. Survival curves were compared with the log-rank test. $\mathrm{P}$ values less than 0.05 were accepted as significant.

\section{Results}

Fifty-seven patients were included in this study, forty of them received docetaxel and seventeen of them received gemcitabine as a second-line therapy. There was no significant difference between the two groups with regard to gender, age, performance status, disease stage, tumor histology and smoking habit. Most of the patients $(94.1 \%)$ in the gemcitabine group had received the cisplatin/docetaxel combination therapy in the first-line setting. Majority of the patients $(55.0 \%)$ in the docetaxel group had received cisplatin/vinorelbine combination (Table 1). Fifty-one patients received at least two cycles of second-line therapy and were evaluable for response, and all patients were evaluable for toxicity.

In the dosetaxel group, the median patient age was 56 years (range, 41-75 years), and the median performance status (ECOG) was 0 (range, $0-2$ ). With regard to gender, 38 patients were male, and 2 patients were female. There were 15 patients with Stage III disease, and 25 patients

Table 1. Table: Characteristics of the Groups

\begin{tabular}{|c|c|c|c|c|}
\hline Characteristics & $\begin{array}{c}\text { Docetaxel } \\
\mathrm{N}(\%)\end{array}$ & $\begin{array}{c}\text { Gemcitabine } \\
\mathrm{N}(\%)\end{array}$ & $\begin{array}{c}\text { Total } \\
\mathrm{N}(\%)\end{array}$ & $\mathrm{p}$ \\
\hline Total patients & $40(70.2)$ & $17(29.8)$ & $57(100)$ & \\
\hline Gender & & & 0.348 & \\
\hline Male & $38(95)$ & $17(100)$ & $55(96.5)$ & \\
\hline Female & $2(5)$ & $0(0)$ & $2(3.5)$ & \\
\hline Age (yrs) & & & & 0.859 \\
\hline Mean \pm standard deviation & $56.8 \pm 8.8$ & $56.4 \pm 7.5$ & $56.6 \pm 8.1$ & \\
\hline Range & $41-75$ & $45-74$ & $41-75$ & \\
\hline Smoking history & & & & 0.227 \\
\hline Nonsmoker & $3(7.5)$ & $0(0)$ & $3(5.3)$ & \\
\hline Ex-smoker & $7(17.5)$ & $1(5.9)$ & $46(80.7)$ & \\
\hline Current smoker & $30(75.0)$ & $16(94.1)$ & $8(14)$ & \\
\hline Performance status (ECOG) & & & & 0.292 \\
\hline 0 & $27(67.5)$ & $10(58.8)$ & $37(64.9)$ & \\
\hline 1 & $10(25)$ & $7(41.2)$ & $17(29.8)$ & \\
\hline 2 & $3(7.5)$ & $0(0)$ & $3(5.3)$ & \\
\hline Stage at initial diagnosis & & & & 0.357 \\
\hline IIIA & $4(10.0)$ & $4(23.5)$ & $8(14.0)$ & \\
\hline IIIB & $11(27.5)$ & $5(29.4)$ & $16(28.1)$ & \\
\hline IV & $25(62.5)$ & $8(47.1)$ & $33(57.9)$ & \\
\hline Histology & & & & 0.356 \\
\hline Squamous cell carcinoma & $21(52.5)$ & $11(64.7)$ & $33(57.8)$ & \\
\hline Adenocarcinoma & $11(27.5)$ & $2(11.8)$ & $13(22.8)$ & \\
\hline Adenosquamous & $0(0)$ & $1(5.8)$ & $1(1.8)$ & \\
\hline Unspecified & $8(17.5)$ & $3(17.6)$ & $11(19.2)$ & \\
\hline Previous first-line chemotherapy & & & & 0.001 \\
\hline Carboplatin/Paclitaxel & $4(10.0)$ & $1(5.9)$ & $5(5.8)$ & \\
\hline Carboplatin/Gemcitabine & $5(12.5)$ & $0(0)$ & $5(8.8)$ & \\
\hline Carboplatin/Vinorelbine & $1(2.5)$ & $0(0)$ & $1(1.8)$ & \\
\hline Cisplatin/Gemcitabine & $6(15.0)$ & $0(0)$ & $6(10.5)$ & \\
\hline Cisplatin/Docetaxel & $2(5.0)$ & $16(94.1)$ & $18(31.6)$ & \\
\hline Cisplatin/Vinorelbine & $22(55.0)$ & $0(0)$ & $22(38.6)$ & \\
\hline Metastasis Site & & & & 0.102 \\
\hline Brain & $7(17.5)$ & $5(29.4)$ & $12(21.1)$ & \\
\hline Bone & $8(20)$ & $1(5.8)$ & $9(15.8)$ & \\
\hline Surrenal & $1(2.5)$ & $0(0)$ & $1(1.7)$ & \\
\hline Other & $1(2.5)$ & $1(5.8)$ & $2(3.5)$ & \\
\hline
\end{tabular}

*ECOG: Eastern Cooperative Oncology Group (ECOG) 

Table 2. Treatment Responses and Survival of Patients

\begin{tabular}{lcccc}
\hline Variables & Dosetaxel $\mathrm{n}(\%)$ & Gemcitabine $\mathrm{n}(\%)$ & Total $\mathrm{n}(\%)$ & $\mathrm{p}$ \\
\hline Response rates (\%) & & & & $>0.05$ \\
$\quad$ Complete response & $0(0)$ & $1(5.8)$ & $1(1.7)$ & \\
$\quad$ Partial response & $3(7.5)$ & $2(11.7)$ & $5(8.7)$ & \\
$\quad$ Stable disease & $9(22.5)$ & $5(29.4)$ & $14(24.5)$ & \\
Progressive disease & $28(70.0)$ & $9(52.9)$ & 8 & \\
Overall response rate (\%) & 12 & $6.8 \pm 4.0$ & $5.4 \pm 3.2$ & 0.02 \\
Chemotherapy cycles-mean & $4.6 \pm 3.0$ & $9.9 \pm 7.6$ & $7.6 \pm 6.1$ & 0.07 \\
PFS* & $6.5 \pm 5.5$ & $24.6 \pm 12.4$ & $22.2 \pm 11.7$ & 0.06 \\
Overall survival (months) & $21.1 \pm 11.4$ & & & 0.313 \\
\hline
\end{tabular}

*PFS=Progression-Free Survival

\section{Table 3 Toxic Effects of the Group}

\begin{tabular}{lrrrr}
\hline Type of Toxicity & \multicolumn{3}{c}{ Dosetaxel Gemcitabine Total } & $\mathrm{p}$ \\
& $\mathrm{n}(\%)$ & $\mathrm{n}(\%)$ & $\mathrm{n}(\%)$ & \\
\hline None & $24(60)$ & $9(52.9)$ & $33(57.9)$ & 0.621 \\
Yes & $16(40)$ & $8(47.1)$ & $24(42.1)$ & 0.303 \\
Anemia & $1(2.5)$ & 0 & $1(1.7)$ & \\
Nausea and vomiting & $2(5)$ & 0 & $2(3.5)$ & \\
Weakness and Anorexia & 0 & $1(5.8)$ & $1(1.7)$ & \\
Hypercalcemia & $1(2.5)$ & 0 & $1(1.7)$ & \\
Liver toxicity & 0 & $1(5.8)$ & $1(1.7)$ & \\
Renal toxicity & 0 & $2(11.7)$ & $2(3.5)$ & \\
Neutropenia & $2(5.0)$ & 0 & $2(3.5)$ & \\
Pneumonia & $4(10.0)$ & $4(23.5)$ & $8(14)$ & \\
Lung toxicity & $1(2.5)$ & 0 & $1(1.7)$ & \\
Thrombophlebitis & $1(2.5)$ & 0 & $1(1.7)$ & \\
\hline
\end{tabular}

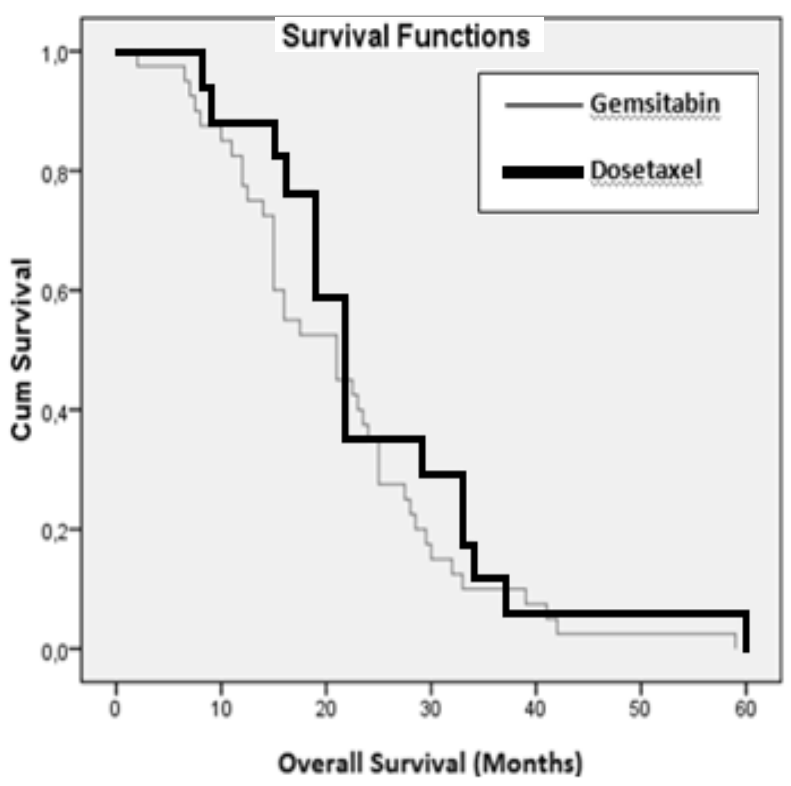

Figure 1. Survival Curves

with Stage IV disease at the time of initial diagnosis. Tumor histology included 11 patients with adenocarcinoma, 21 patients with squamous cell carcinoma, and seven patients with tumors of unspecified histology. Four of them had received paclitaxel/carboplatin, 5 of them gemcitabine/ carboplatin, one patient vinorelbine/carboplatin, 6 of them gemcitabine/cisplatin, 2 of them docetaxel/cisplatin, 22 of them vinorelbine/cisplatin as firstline chemotherapy.

In the gemcitabine group, the median patient age was 56.4 years (range, 45-74 years), and the median performance status (ECOG) was 0 (range, 0-2). With regard to gender, all of the 17 patients were male. There were 9 patients with Stage III disease, and 8 patients with Stage IV disease at the time of initial diagnosis. Tumor histology included 2 patients with adenocarcinoma, 11 patients with squamous cell carcinoma, 1 patient with adenosquamous carcinoma and three patients with tumors of unspecified histology. Only one patient had received paclitaxel/carboplatin and the rest of the patients had received docetaxel/cisplatin as a first line chemotherapy.

Six patients $(10.6 \%)$ were resistant to first-line treatment (experienced progressive disease (PD) or recurrent disease within 3 months from completion of first-line treatment), whereas the remaining 51 patients $(89.4 \%)$ were sensitive to platinum-based therapy and experienced disease recurrence after a prior response that lasted 3 months from the end of first-line chemotherapy. Three $(7.5 \%)$ patients showed a partial response (PR), $9(22.5 \%)$ stable disease (SD), and $28(70 \%)$ PD in the docetaxel group. One $(5.8 \%)$ complete response was observed in gemcitabine group. Two $(11.7 \%)$ patients showed PR, 5 (29.4\%) SD, and $9(52.9 \%)$ PD. The overall response rate was $12 \%$ within the docetaxel group. In the gemcitabine group, the overall response rate was $8 \%$, this difference was statistically significant $(p=0.02)$. The mean number of chemotherapy cycles was $6.8 \pm 4.0$ in the gemcitabine group, on the other hand it was 4.6 \pm 3.0 in the docetaxel group.

The median OS was 21 months; the median PFS was 5 months in the gemcitabine group and the median OS was 22 months, the median PFS was 8 months in the docetaxel group. Altough PFS was longer in the gemcitabine group, it was not statistically significant $(\mathrm{p}=0.06)$ (Figure 1).

Toxic effects are shown in Table 3 . All side effects were grade $1 / 2$. There was no difference between the two groups in terms of incidence of the adverse affects ( $40 \% \mathrm{vs}$ $47.1 \% \mathrm{p}=0.303$ ). Hematological toxicity was reported by 3 $(7.5 \%)$ patients in the docetaxel group. No hematological side effect was seen in the gemcitabine group. None of the patients experienced grade $3 / 4$ neutropenia. No major toxicity was encountered to stop the drug for both groups. Patients receiving gemcitabine were more likely to have nonhematological side effects. One patient had weakness and anorexia, liver enzymes was elevated in one patient, two patients had renal toxicity and 4 patients developed pneumonia.

\section{Discussion}

Platinum-based chemotherapy was the standard 
first-line treatment for locally advanced or metastatic NSCLC. However, nearly all patients exposed to firstline chemotherapy eventually experience progression. At present, docetaxel was the commonly used secondline chemotherapy for advanced NSCLC, but the benefit was modest. There are only few agents approved for second-line chemotherapy of advanced NSCLC including docetaxel, pemetrexed and erlotinib (Juergens et al., 2007; Fossella et al., 2000, Shepherd et al., 2000). In this study, we evaluated the affectivity and toxicity profiles of single agent gemcitabine and docetaxel in the second-line treatment and according to our knowledge, this is the first report to compare second-line gemsitabine with docetaxel for advanced NSCLC patients from Turkey.

Docetaxel has been extensively evaluated in the second-line setting. Seven Phase II trials of this agent have been reported, enrolling a total of 312 patients who were treated with docetaxel $100 \mathrm{mg} / \mathrm{m}^{2}$ every 3 weeks. Overall response rates (OR) ranged from 14-24\%, and the median survival time was between 6 and 11 months in these studies (Burris et al., 1993, Yokoyama et al., 1994, Chevalier et al., 1995, Fossella et al., 1995, Mattson et al., 1996, Robinet et al., 1996, Gandara et al., 1997, Robinet et al., 1997). In our study OR of dosetaxel was found $12 \%$ and the 21 months median survival in our study is similar to the median survival achieved in previous studies.

In one study, overall response rates of $11.9 \%$ and $7.5 \%$ were obtained for docetaxel at doses of $100 \mathrm{mg} / \mathrm{m}^{2}$ and 75 $\mathrm{mg} / \mathrm{m}^{2}$, respectively (Fossella et al., 2000). In our study, overall response rate was $12 \%$.

The side-effects reported from the previous studies with docetaxel including diarrhoea, neuropathy, and grade 3 and 4 neutropenia were not seen in our patients. The most common side affects were pneumonia and grade $1 / 2$ neutropenia with the rate of $10.0 \%$ and $5 \%$ respectively. One of the reasons for the less side effects may be the higher performance scores $(92.5 \%)$ of our patients. Before and after the each cycle of chemotherapy, complete blood count and biochemistry values of the all patients closely followed. Chemotherapy was received if WBC count above 1.000/dl and platelet above 50.000/dl. Close monitarization may be the another reason for the apperance of the less side affects.

Phase II trials, evaluating activity and tolerability of single agent gemcitabine as second line chemotherapy, demonstrated response rates ranging from $6 \%$ to $20.6 \%$ (Crino et al., 1999, Gridelli et al., 1999, Van Kooten et al., 1999, Gillenwater et al., 2000, Sculier et al., 2000, van Putten et al., 2001, Lara et al., 2004).

Cho et al. tested gemcitabine as single agent in 83 platinum pretreated patients with advanced NSCLC. In this study, patients received gemcitabine $1000 \mathrm{mg} / \mathrm{m}^{2}$ once a week for 3 weeks every 28 days. Sixteen patients (19\%) achieved a partial response (PR) to treatment; the median duration of response was 29 weeks (Cho et al., 2006). In our study, patients received gemcitabine $1.250 \mathrm{mg} / \mathrm{m}^{2}$ on days 1 and 8 , followed by a 1 -week rest repeated every 3 weeks. One (5.8\%) complete response was observed, two (11.7\%) patients showed a PR.

In another study, Gridelli et al. evaluated a 4-week schedule of single agent gemcitabine in 30 platinum- pretreated advanced NSCLC patients. Six (20\%) partial responses were observed, two of which in patients progressing during first line chemotherapy (Gridelli et al., 1999).

Crino et al. and Cho et al. reported 34 and 38 weeks of median overall survival respectively (Crino et al., 1999, Cho et al., 2006). In our study, the median survival of patients who received gemcitabine was 22 months. Median time to disease progression was 8 months. Gemcitabine was well tolerated in our patient population. Among all of the chemotherapy cycles, we had not observed any grade 3 and 4 toxicities.

In previous studies, overall response rate was between $18.5 \%$ and $19 \%$ in the treatment of single agent gemcitabine as a second treatment (Cho et al., 2006, Coskun et al., 2008). Overall response rate was higher in the group receiving docetaxel (12\% vs $8 \%)$ and PFS and OS were longer in the gemcitabine group (but not istatistically sagnificant).

We concluded that docetaxel and gemsitabine are statistically equivalent in terms of OS and toxicity. Treatment with gemcitabine demonstrated clinically equivalent efficacy with a significantly improved safety profile compared with those receiving docetaxel in the second-line setting for advanced NSCLC in this study. Based on these results, treatment with gemcitabine should be considered a standard treatment option for second-line NSCLC.

\section{References}

Burris H, Eckhardt J, Fields S, et al (1993). Phase II trial of Taxotere with non-small cell lung cancer. Proc Am Soc Clin Oncol, 12, 335.

Cho KH Song YB, Choi IS, et al (2006). A phase II study of single-agent gemcitabine as a second-line treatment in advanced non-small cell lung cancer. Jpn J Clin Oncol, 36, 50-4.

Cobo M, Gutiérrez V, Alcaide J, et al (2007). A phase II study of days 1 and 8 combination of docetaxel plus gemcitabine for the second-line treatment of patients with advanced nonsmall-cell lung cancer and good performance status. Lung Cancer, 56, 255-62.

Coskun U, Kaya AO, Buyukberber S, et al (2008). Single agent gemcitabine in the second-line treatment of advanced nonsmall cell lung cancer after treatment with taxane + platinum regimens. Med Oncol, 25, 133-6.

Crino L, Mosconi AM, Scagliotti GV, et al (1999). Gemcitabine as second-line treatment for advanced non-small-cell lung cancer, A phase II trial. J Clin Oncol, 17, 2081-5.

Fossella FV, De Vore R, Kerr RN, et al (2000). Randomized Phase III trial of docetaxel versus vinorelbine or ifosfamide in patients with advanced non-small cell lung cancer previously treated with platinum-containing chemotherapy regimens. J Clin Oncol, 18, 2354-62.

Fossella FV, Lee JS, Shin DM, et al (1995). Phase II study of docetaxel for advanced or metastatic platinum-refractory non-small-cell lung cancer. J Clin Oncol, 13, 645-51.

Gandara DR, Vokes E, Green M, et al (1997). Docetaxel (Taxotere) in platinum-treated non-small cell lung cancer, a confirmation of prolonged survival in a multicenter trial. Proc Am Soc Clin Oncol, 16, 454a.

Gillenwater HH, Tynan M, Natoli S, et al (2000). Second-line gemcitabine in refractory stage IV non-small-cell lung 

cancer, A phase II trial. Clin Lung Cancer, 2, 133-8.

Gridelli C, Perrone F, Gallo C, et al (1999). Single-agent gemcitabine as second-line treatment in patients with advanced non small cell lung cancer (NSCLC), A phase II trial. Anticancer Res, 19, 4535-8.

Hertel LW, Boder GB, Kroin JS, et al (1990). Evaluation of the antitumor activity of gemcitabine (20, 20-difluoro-20deoxycytidine). Cancer Res, 50, 4417-22.

Juergens R, Brahmer J, Ettinger D (2007). Gemcitabine and vinorelbine in recurrent advanced non-small cell lung cancer, sequence does matter. Cancer Chemother Pharmacol, 59, 621-9.

Kosmas C, Tsavaris N, Syrigos K, et al (2007). A phase I-II study of bi-weekly gemcitabine and irinotecan as secondline chemotherapy in non-small cell lung cancer after prior taxane + platinum-based regimens. Cancer Chemother Pharmacol, 59, 51-9.

Lara PN Jr, Gumerlock PH, Mack PC, et al (2004). Gemcitabine in patients with nonsmall-cell lung cancer previously treated with platinum-based chemotherapy, A phase II California cancer consortium trial. Clin Lung Cancer, 6, 102-7.

Le Chevalier T. (1995). Docetaxel, meeting the challenge of nonsmall cell lung cancer management. Anticancer Drugs, 6, 13-7.

Lund B, Kristjansen PEG, Hansen HH (1993). Clinical and preclinical activity of 20,20-difluoro-20difluorodeoxycytidine (gemcitabine). Cancer Treat Rev, 19, 45-55.

Mattson K, Le Chevalier T, Stupp R, et al (1996). Preliminary report of Phase II study of docetaxel (Taxotere ${ }^{\circledR}$ ) in locally advanced or metastatic non-small cell lung cancer. Ann Oncol, 7, 429a.

Robinet G, Kleisbaurer JP, Thomas P, et al (1996). Phase II study of Taxotere (docetaxel) in advanced or metastatic non-small cell lung cancer previously treated with platinum. Ann Oncol, 7, 96-7.

Robinet G, Kleisbaurer JP, Thomas P, et al (1997). Phase II study of docetaxel (Taxotere) in first and second-line NSCLC. Proc Am Soc Clin Oncol, 16, 480.

Sculier JP, Lafitte JJ, Berghmans T, et al (2000). A phase II trial testing gemcitabine as second-line chemotherapy for non small cell lung cancer. The European Lung Cancer Working Party. Lung Cancer, 29, 67-73.

Shepherd F, Dancey J, Ramlau R, et al (2000). Prospective randomized trial of docetaxel versus best supportive care in patients with non-small cell lung cancer previously treated with platinum-based chemotherapy. J Clin Oncol, 18, 2095-103.

Van Kooten M, Traine G, Cinat G, et al (1999). Single agent gemcitabine in pretreated patients with non-small-cell lung cancer, results of an Argentinean multicentre phase II trial. Br J Cancer, 81, 846-9.

van Putten JW, Baas P, Codrington H (2001). Activity of singleagent gemcitabine as second-line treatment after previous chemotherapy or radiotherapy in advanced non-small-cell lung cancer. Lung Cancer, 33, 289-98.

Yokoyama A, Kurita Y, Watanabe K (1994). Early phase II clinical study of RP56976 (docetaxel) in patients with primary pulmonary cancer, docetaxel cooperative study group for lung cancer. Gan To Kagaku Ryoho, 21, 2609-16. 